\title{
La Séptima de Beethoven: la segunda Eroica*
}

\author{
Beethoven's Seventh: the second Eroica
}

Constantin Floros

Universidad de Hamburgo

\section{RESUMEN}

El presente artículo está centrado en el estudio de la Séptima Sinfonía de Ludwig van Beethoven (1770-1827) y en sus semejanzas estilísticas con la Sinfonía $n^{\circ} 3$, por lo puede ser considerada como una segunda Sinfonía Eroica. Para ello se ha tenido en consideración las circunstancias que dieron lugar a su creación, así como las opiniones de contemporáneos del autor como Czerny y Ries o las visiones de Wagner y Mahler. El autor defiende asimismo que han pasado desapercibidas otras similitudes con obras de carácter heroico: la Danza eroica $\mathrm{n}^{\circ} 8$ del ballet "heroico-alegórico" Las Criaturas de Prometeo op. 43 y la variación en sol menor del "Finale" de la propia Sinfonía Eroica (1803). Asimismo se ha tenido en cuenta la influencia ejercida por los acontecimientos políticos de su tiempo en el origen de obras como La victoria de Wellington.

Palabras clave: Beethoven, Séptima Sinfonía, Heroísmo, Stadler, Czerny.

* Traducción de Paulino Capdepón Verdú. 


\title{
CONSTANTIN FLOROS
}

\begin{abstract}
This article focuses on the study of Ludwig van Beethoven's (1770-1827) Seventh Symphony and its stylistic similarities to Symphony No. 3, so it can be considered a second Eroic Symphony. For this reason, the circumstances that gave rise to its creation have been taken into consideration, as well as the opinions of the author's contemporaries such as Czerny and Ries or the visions of Wagner and Mahler. The author also argues that other similarities with works of a heroic nature have gone unnoticed: the Danza eroica no. 8 from the "heroicallegoric" ballet The Creatures of Prometheus op. 43 and the variation in G minor of the "Finale" from the Eroica Symphony itself (1803). The influence of political events of the time on the origin of works such as Wellington's Victory has also been taken into account.
\end{abstract}

Key Words: Beethoven, Seventh Symphony, heroism, Stadler, Czerny.

Floros, C. (2020). La Séptima de Beethoven: la segunda Eroica. Cuadernos de Investigación Musical, (11, número extraordinario), pp. 5-14.

Considerado en su totalidad, el legado sinfónico de Ludwig van Beethoven se presenta como un universo sonoro que abarca los más diversos niveles de expresión: lo heroico, lo "romántico", lo trágico, lo contemplativo, lo humorístico, lo sublime y lo religioso. Cada una de las nueve sinfonías está impregnada de un carácter individual. Se puede comprobar con algunos ejemplos: la Eroica frente a la Cuarta; la sonoridad trágica de la Quinta frente a la Pastoral; o bien la Séptima frente a la "humorística" Octava. El resultado no es más que parejas de obras desiguales. De todas sus sinfonías es la Séptima la más luminosa y radiante, la única escrita con sostenidos en la brillante tonalidad de La mayor ${ }^{1}$.

Y sobre todo se diferencia también de sus hermanas en tanto que el ritmo de todas sus frases se revela como el más importante factor de la configuración de la obra. Es por ello comprensible que Richard Wagner la entendió como una "apoteosis de la danza". En su fundamental tratado Das Kunstwerk der Zukunft [La obra de arte del futuro] escribió lo siguiente:

\footnotetext{
${ }^{1}$ El carácter radiante de la sinfonía puede explicar la razón de la renuncia a los trombones. Sobre la obra y su historia véase en especial Riethmüller, Dahlhaus \& Ringer, 1994, pp. 45-62.
} 
Alles Ungestüm, alles Sehnen und Toben des Herzens wird hier zum wonnigen Übermute der Freude, die mit bacchantischer Allmacht uns durch alle Räume der Natur, durch alle Ströme und Meere des Lebens hinreißt, jauchzend selbstbewusst überall, wohin wir im kühnen Takte dieses menschlichen Sphärentanzes treten. Diese Sinfonie ist die Apotheose des Tanzes selbst: sie ist der Tanz nach seinem höchsten Wesen, die seligste Tat der in Tönen gleichsam idealisch verkörperten Leibeswegung ${ }^{2}$ (Wagner, 1850, p. 94).

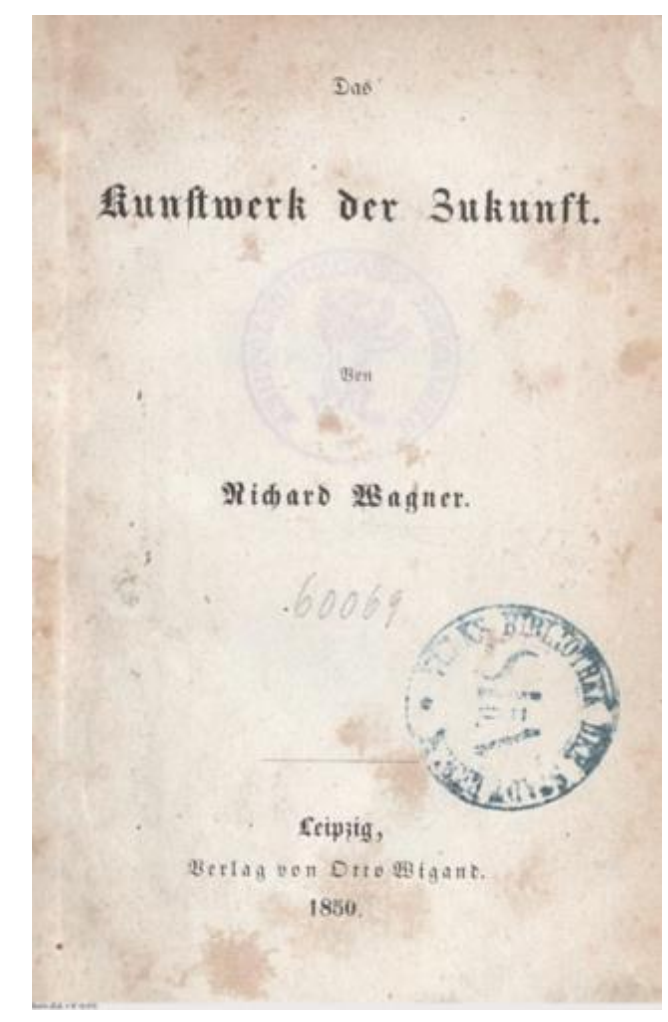

Fig. 1: Richard Wagner: Das Kunstwerk der Zukunft (Leipzig, 1850).

Tras una interpretación de la Séptima el 19 de marzo de 1899 en Viena, Gustav Mahler destacó el "efecto dionisíaco" que la última parte había ejercido en todos los oyentes (Killian, 1984, p. 130), mientras que otros hablaron del efecto ditirámbico de la obra; como es bien sabido, bajo la denominación de "dithyrambus" se entiende una antigua canción coral griega y danza circular que describe los actos y sufrimientos de Dionisio y otros dioses y héroes, glorificados en la emoción extática.

\footnotetext{
2 Toda la impetuosidad, todo el anhelo y la furia del corazón se convierte aquí en feliz exuberancia de la alegría, que con la omnipotencia bacanal nos ha impulsado a través de todos espacios de la naturaleza, de todos los arroyos y mares de la vida, jubiloso y confiado en todas partes, gritando...y nos sentimos confiados dondequiera que vayamos con los audaces golpes de este humano... de la danza de las esferas. Esta sinfonía es la apoteosis misma de la danza, es la danza según su más alta esencia, el acto más bendito de la historia de la humanidad que resuena como si fuera un movimiento corporal idealmente encarnado.
} 


\section{CONSTANTIN FLOROS}

En mi opinión, la increíblemente vital Séptima se puede comparar en varios aspectos con la Eroica, existiendo incluso entre las dos obras múltiples paralelismos. Sorprendentemente, hasta ahora ha pasado desapercibido que varias secciones del "Finale" de la Séptima (cc. 52-62) ofrecen los mismos rasgos que dos obras "heroicas" de Beethoven: nos referimos concretamente a la Danza eroica n” 8 del ballet "heroico-alegórico" Las Criaturas de Prometeo op. 43 (1800/01) y la variación en sol menor del "Finale" de la Eroica (1803) (Floros, 2008, pp. 70-73, p. 106 y Tabla 1): ostinati con puntillos y al mismo tiempo ritmos aporreantes otorgan a ambas composiciones "heroicas" un sello propio. Tal como los bocetos del primer movimiento de la Séptima claramente muestran, Beethoven partió asimismo de un ritmo de puntillo de la "introducción lenta" del siguiente "Vivace" en compás de 6/8, que domina extensos fragmentos del movimiento (cinco sextas partes) y al que parecen estar subordinadas tanto la melodía como la armonía (Nottebohm, 1887, pp. 101-105). Por último, es particularmente significativo para la concepción de este movimiento que el principio de dualidad contrastante de los temas en los movimientos con forma de sonata, que es tan vinculante para la música del Clasicismo, aquí está visiblemente debilitado: tanto el tema principal como el denominado tema secundario, presentan la misma concepción rítmica. Sólo se abandona más tiempo el ritmo principal en la Coda, donde un "Basso ostinato" binario que se repite once veces prepara la entrada de la sección cadencial final mediante una violenta gradación dinámica.

Walter Riezler (1936, p. 169) señaló con razón que en ninguna otra obra de Beethoven todos los movimientos están tan fuertemente dominados por el ritmo como en la Séptima. Ello es aplicable por supuesto al segundo movimiento, el célebre "Allegretto" en la menor y compás binario, que parece recordar lo procesional ${ }^{3}$, dividiéndose en cinco secciones según el esquema formal A-B-A1-B1-A2, en el que las secciones B a manera de trío están en La mayor. Determinante para la estructura de las partes A son un ritmo uniforme y repetido que consiste en un dáctilo y un espondeo, como puede observarse en el siguiente ejemplo (Figura 2):

\footnotetext{
${ }^{3}$ Según Wolfgang Osthoff, el “Allegretto” entraña algo del carácter de la letanía. Véase Osthoff, 1977, pp. 150179.
} 


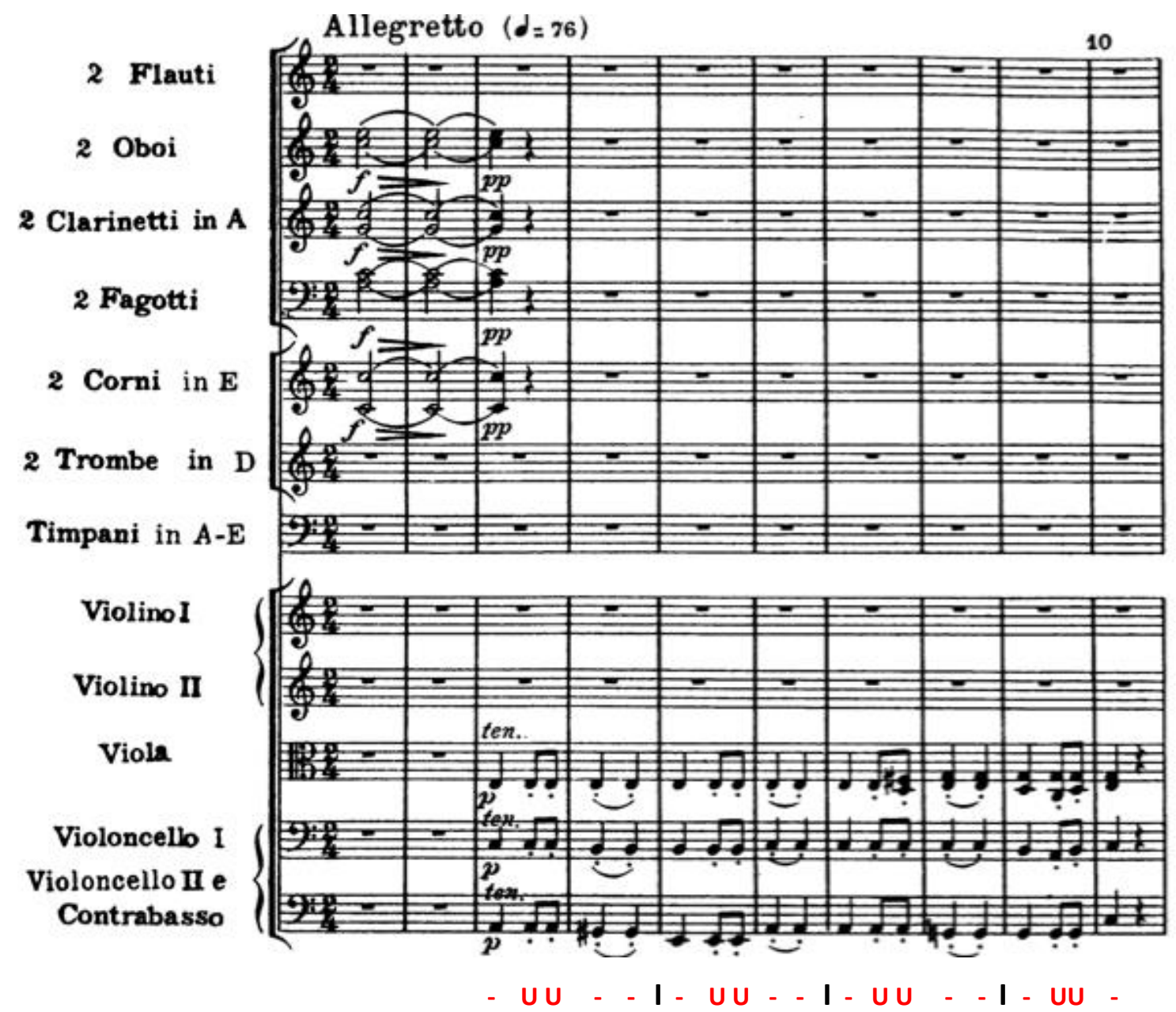

Fig. 2: Ludwig van Beethoven: Séptima Sinfonía, $2^{\circ}$ movimiento (cc. 1-10).

Para la impresión auditiva suscitada, es decisivo que el movimiento se inicie y finalice con un acorde de cuarta y sexta en la menor, ampliamente mantenido en el viento metal (un evidente y doloroso símbolo sonoro), y que el tono básico elegíaco de las partes principales sea manifiesto en las secciones en La mayor a manera de trío. Beethoven había anotado el tema principal del movimiento aproximadamente seis años antes de la concepción de la Séptima con motivo de la composición del Cuarteto de cuerda en Do mayor op. 59 y en un primer momento dejado de lado. Sólo durante el trabajo con la Séptima lo retomó (Nottebohm, 1887, p. 106s).

En el tercer movimiento pentapartito, que asume la función del scherzo, Walter Riezler comentó acertadamente que su parte principal es "en sus anhelantes negras más relajado rítmicamente y menos incisivo" que los dos primeros movimientos (Riezler, 1936, p. 170). Lo más notable es el vivo contraste entre la ágil la parte principal en Fa mayor y la festiva e hímnica doble sección media en Re mayor a la manera de trío. Según el creíble informe de Maximilian Stadler, Beethoven obtuvo la melodía de este Trío de una canción de romería, originaria una Baja Austria (Wheelock Thayer, 1923, p. 302) -una declaración que también es relevante para la interpretación de la Séptima. De manera interesante participan las cuerdas y los vientos en las partes principales en igualdad de condiciones, mientras que en el 


\section{CONSTANTIN FLOROS}

ceremonial Trío domina la sonoridad del viento metal. El movimiento de la Séptima más complicado desde el punto de vista rítmico es el "Finale", el cual ofrece una colorida imagen de variedad rítmica: estructuras téticas y anacrúsicas sucediéndose alternativamente en varias ocasiones, ritmos de puntillo en ostinato, animadas síncopas y sforzati sobre partes débiles del compás otorgan a la composición una energía increíble -por momentos resuena la música como si fuera una marcha rápida en $4 / 4$, aunque está escrita en $2 / 4$.

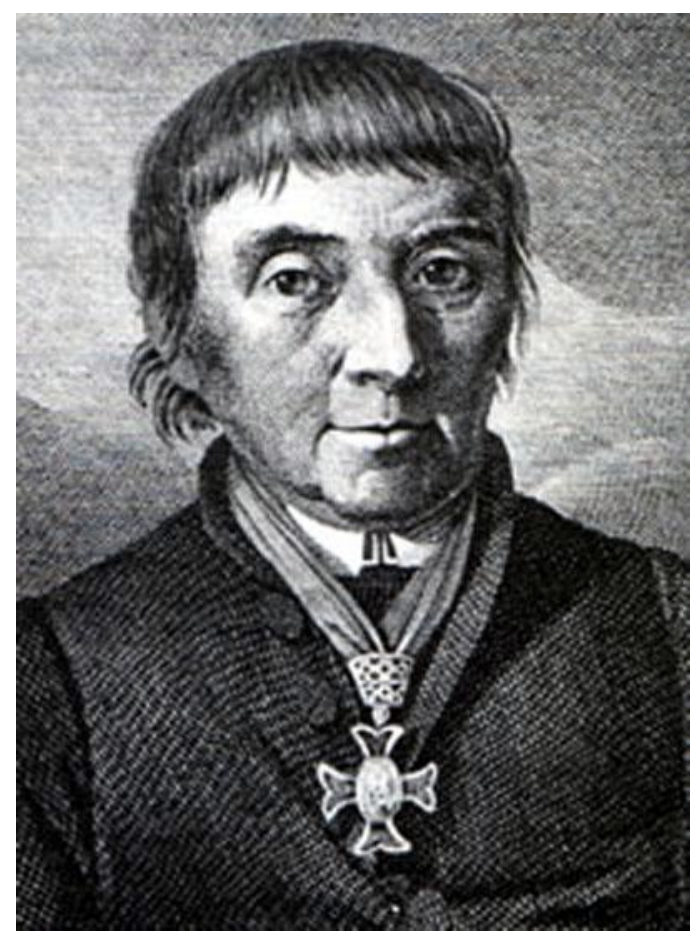

Fig. 3: Maximilian Stadler (1818).

Beethoven trabajó en la Séptima desde el otoño de 1811 hasta junio de 1812 y con el manuscrito de la partitura comenzó el 13 de mayo de 1812, de acuerdo con la datación del autógrafo de la partitura. Originalmente, había pensado en dar a conocer la Sinfonía en una academia de las "Venerables Ursulinas", pero finalmente sólo se estrenó el 8 de diciembre de 1813 en la sala de la universidad de Viena, junto con la "Sinfonía de batalla" Wellingtons Sieg oder die Schlacht bei Vittoria op. 91. Esta y las siguientes interpretaciones constituyeron un éxito fenomenal: en una de las críticas, Beethoven fue descrito como "el más grande compositor de nuestro tiempo" (Wiener Allegemeine Zeitung, finales de 1813. Véase Kunze, 1987, p. 268), y la propia obra fue alabada como la "más melodiosa, agradable y comprensible" sinfonía compuesta hasta entonces (Wiener Allegemeine Zeitung, comienzos de 1814. Véase Kunze, 1987, p. 270). Gustaba tanto el "Allegretto" que debía ser repetido. La "Sinfonía de batalla", estrenada al mismo tiempo que la Séptima, fue compuesta entre agosto y noviembre de 1813 por sugerencia del mecánico Johann Nepomuk Mälzel, bien conocido como inventor del metrónomo, como una especie de homenaje musical por la derrota de las tropas de Napoleón en Vitoria, una ciudad española. Los lectores que no estén familiarizados con la biografía de Beethoven pueden sorprenderse por el hecho de que el anteriormente 
admirador de Napoleón (al cual había dedicado originalmente la Eroica) pudiera crear ahora una obra de este tipo, que, por lo demás, tras el sensacional éxito inicial fue criticada numerosas veces y hoy en día se ha convertido en el Parerga de Beethoven (Riethmüller, 1994, pp. 34-35). Se pueden comprender mejor los motivos que motivaron la composición de esta "Sinfonía de batalla" si se tienen en cuenta tanto la amenaza de Napoleón y el cambio en las condiciones políticas. Sobre esta cuestión, se tratará posteriormente.

En 1842, el alumno de Beethoven, Carl Czerny, informó que su maestro se había dejado inspirar en muchas de sus obras más bellas gracias a sus propias visiones e imágenes literarias. A este respecto mencionó como ejemplos concretos el "Adagio" en Mi Mayor del Cuarteto de Cuerdas en mi menor op. 59, $n^{\circ} 2$ y la Séptima. Por último, Beethoven -como Czerny afirmó-, al igual que Wellingtons Sieg oder die Schlacht bei Vittoria, se sintió influenciado por los sucesos de 1813 y 1814 (Czerny, ed. de Badura-Skoda, 1963, p. 62). Esta información es incorrecta ya que la Séptima, como se ha mencionado con anterioridad, ya se había completado en junio de 1812.

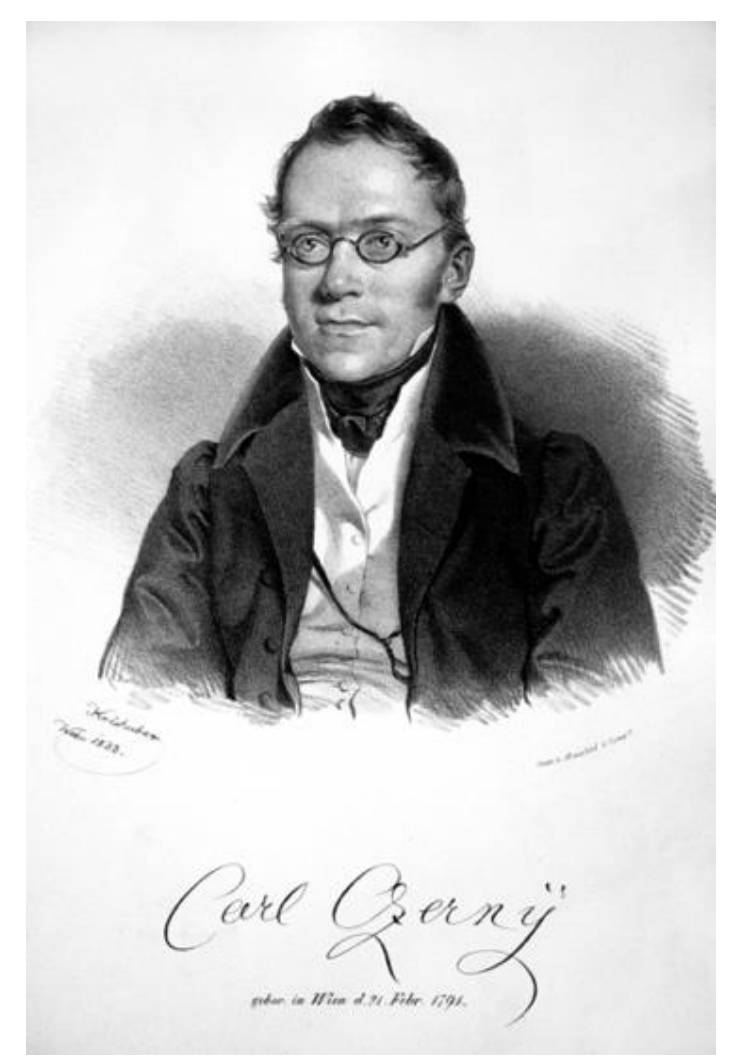

Fig. 4: Carl Czerny (litografía de Josef Kriehuber, 1833)

Sin embargo, existen numerosos indicios de que los emocionantes acontecimientos en la política internacional de este período también tuvieron una impronta en la concepción de la sinfonía. Así, la inicial simpatía de muchos intelectuales de orientación republicana por el Primer Cónsul de la joven República Francesa se transformó en indignación y rechazo ilimitados tras su proclamación imperial en 1804, los cuales se incrementaron aún más en 


\section{CONSTANTIN FLOROS}

Viena cuando las tropas francesas ocuparon la ciudad por primera vez en 1805 . En mayo de 1809 , volvieron a invadir los suburbios y bombardearon la ciudad imperial en la noche del 11 al 12 de mayo. Según Ferdinand Ries, Beethoven estaba "muy asustado" durante aquella época (Wegeler \& Ries, 1906, p. 14), pero encontró la fuerza para esbozar una canción patriótica con texto de Heinrich Joseph von Collin creando una pieza de batalla que debería finalizar con la victoria (Nottebohm, 1887, p. 262s). A partir de este hecho se puede observar que Beethoven estuvo rumiando planes para una "Sinfonía de batalla" varios años antes de componer Wellingtons Sieg. En una carta a su editor Gottfried Christoph Härtel del 26 de julio de 1809 Beethoven describió su estado anímico durante la ocupación: "Welch zerstörendes, wüstes Leben um mich her, nichts als Trommeln, Kanonen, Menschenelend in aller Art" [Qué vida destruida y desolada a mi alrededor, nada más que tambores, cañones, miseria humana de todo tipo] (Brandenburg, 1996, p. 71). Después de ello, parece plausible que la Séptima, en cuyo trío una canción de peregrinación austriaca y en cuyo final decididos elementos heroicos llaman la atención, fuera concebida como una glorificación de lo "heroico".

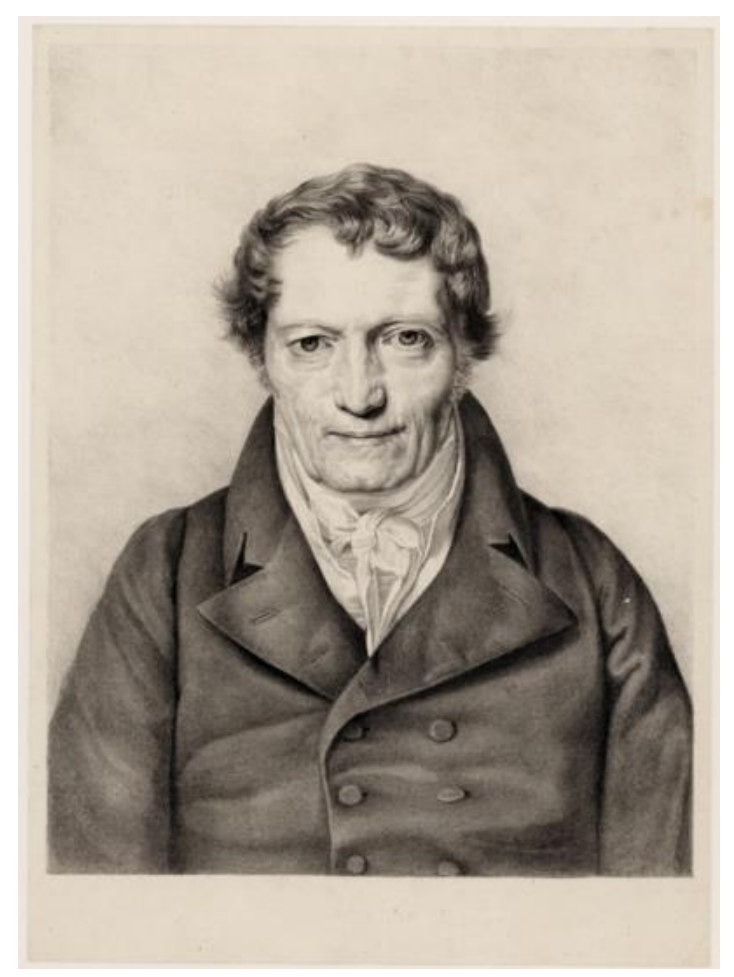

Fig. 5: Gottfried Christoph Härtel (1763-1827).

\footnotetext{
${ }^{4}$ Sobre la connotación política de la sinfonía, véase Schönewolf, 1953, pp. 590-636. Arnold Schering defendió la tesis (no fundamentada) que Beethoven se inspiró en escenas de Wilhelm Meister Lebrjahre de Goethe: véase Schering, 1936, pp. 211-236.
} 
Entonces, ¿se sintió Beethoven como un patriota? Su relación con la corte imperial en Viena era notoriamente ambivalente. Por otro lado, un visitante francés anotó en 1809 en su diario que Beethoven había extendido su rechazo por Bonaparte a todo el pueblo francés, el cual "se había sometido a su yugo". "Sin embargo", añadió el visitante, "se ocupó mucho de la grandeza de Napoleón" (Frimmel, 1926, pp. 336s). En una nota de un boceto del año 1810 se puede leer la siguiente noticia: "Einige große Werke geschrieben, die mich mit Frankreich in Verbindung bringen und in den Zeitungen Aufsehen machen, die Messe (op. 86) könnte vielleicht auch dem Napoleon dediciert werden" [Algunas grandes obras escritas me sugieren a Francia y causan sensación en los periódicos: la Misa (op. 86) pudo ser dedicada también a Napoleón] (Floros, 2008, p. 129. Lo cierto es que después de 1813 Beethoven esperaba el apoyo de los enemigos de Napoleón. Así que dedicó conscientemente Wellingtons Sieg a Jorge IV, por entonces Príncipe Regente de Inglaterra, y las tres adaptaciones pianísticas de la Séptima a la zarina Isabel Alexieva (Kinsky \& Halm, 1955, p. 260). Sin embargo, sería erróneo subestimar el oportunismo de Beethoven: al menos desde el inicio de la política anti-británica de Napoleón comenzó a ver un estado ideal en Gran Bretaña, la tierra de la libertad por excelencia, e incluso se planteó emigrar a Inglaterra tras el Congreso de Viena en 1814 (Magnani, 1967, pp. 30-42).

\section{BIBLIOGRAFÍA}

Brandenburg, S. (Ed.) (1996). Ludwig van Beethoven. Briefwechsel. Gesamtausgabe, vol. 2. Múnich: G. Henle.

Czerny, C. (1963). Über den richtigen Vortrag der sämtlichen Beethoven'schen Klavierwerke [ed. de P. Badura-Skoda]. Viena: Universal Edition.

Floros, C. (2008). Beethovens Eroica und Prometheus-Musik. Sujet-Studien [2 edición]. Wilhelmshaven: Heinrichshofen.

Frimmel. T. (1926). Beethoven-Handbuch, vol. 2. Leipzig: Breitkopf \& Härtel.

Wegeler, F. G. \& Ries, F. (1906). Biographische Notizen über Ludwig van Beethoven [2ª edición, ed. de A. C. Lalischer]. Berlín/Leipzig: Schuster \& Loeffler.

Killian, G. (Ed.) (1984). Gustav Mabler in den Erinnerungen von Natalie Bauer-Lechner. Hamburgo: Karl Dieter Wagner.

Kinsky, G. \& Halm, H. (Eds.) (1955). Das Werk Beethovens. Thematisch-bibliographisches Verzeichnis seiner sämtlichen vollendeten Kompositionen. Múnich: G. Henle. 


\section{CONSTANTIN FLOROS}

Kunze, S. (Ed.) (1987). Ludwig van Beethoven. Die Werke im Spiegel seiner Zeit. Gesammelte Konzertberichte und Rezensionen bis 1830. Laaber: Laaber Verlag.

Magnani, L. (1967). Beethovens Konversationshefte. Múnich: R. Piper.

Nottebohm, G. (1887). Zweite Beethoveniana. Nachgelassene Aufsätz̧e. Leipzig: Peters.

Osthoff, W. (1977). Zum Vorstellungsgehalt in Beethoven 7. Symphonie. Archiv für Musikwissenschaft, 34, pp. 150-179.

Riethmüller, A., Dahlhaus, C. \& Ringer, A. L. (Eds.) (1994). Beethoven. Interpretationen seiner Werke, vol. 2. Laaber: Laaber Verlag.

Riethmüller, A. (1994). Wellingtons Sieg Oder die Schlacht bei Vittoria op. 91. En A. Riethmüller; C. Dahlhaus \& A. L. Ringer (Eds.). Beethoven. Interpretationen seiner Werke, vol. 2 (pp. 34-45.) Laaber: Laaber Verlag.

Riezler, W. (1936). Beethoven [2a edición]. Berlín/Zúrich: Atlantis Verlag.

Schering, A. (1936). Beethoven und die Dichtung. Berlín: Junker und Dünnhaupt.

Schönewolf, K. (1953). Beethoven in der Zeitenwende, vol. 2. Halle: Mitteldeutscher Verlag.

Wagner, R. (1850). Das Kunstwerk der Zukunft. En Sämtliche Schriften und Dichtungen (1913) [6 ${ }^{\mathrm{a}}$ edición], vol. 3. Leipzig: Breitkopf \& Härtel.

Wheelock Thayer, A. (1923). Ludwig van Beethoven's Leben [ed. de H. Deiters \& H. Riemann, $3^{\mathrm{a}}-5^{\mathrm{a}}$ edición], vol. 3. Leipzig: Breitkopf \& Härtel.

Wiener allgemeine musikalische Zeitung.

Fecha de recepción: 11/11/2020

Fecha de aceptación: 20/11/2020 